American Journal of Pharmacology and Toxicology 3 (1): 111-124, 2008

ISSN 1557-4962

(C) 2008 Science Publications

\title{
Hormetic and Non-Hormetic Dose-Response Functions in Stress Effects on Memory and Synaptic Plasticity: Issues and Mechanisms
}

\author{
${ }^{1,2,4}$ Phillip R. Zoladz and ${ }^{1,2,3,4}$ David M. Diamond \\ ${ }^{1}$ Medical Research Service, VA Hospital, Tampa, Florida 33612 \\ ${ }^{2}$ Department of Psychology, ${ }^{3}$ Department of Molecular Pharmacology and Physiology, \\ ${ }^{4}$ Center for Preclinical and Clinical Research on PTSD, \\ University of South Florida, Tampa, Florida
}

\begin{abstract}
Over a century of behavioral research has shown that stress can exert both positive and negative effects on memory. We have explored the idea that the complex effects of stress on learning and memory can be characterized by hormetic- and non-hormetic dose-response functions, in which stress may either stimulate or impair brain memory mechanisms, depending, in part, on the timing and duration of the stress experience. Extensive work has shown that acute stress or corticosteroid administration has a biphasic effect specifically on hippocampus-dependent learning, memory and synaptic plasticity. We suggest that brief stress exerts a rapid enhancement of memory-related functions of the hippocampus, produced by the amygdala-induced activation of hippocampal synaptic plasticity in conjunction with excitatory effects of neuromodulators, including glucocorticoids, norepinephrine, corticotropin-releasing hormone, acetylcholine and dopamine. We propose that the rapid stress-induced activation of the amygdala-hippocampus brain memory system results in a linear (non-hormetic) dose-response relation between emotional strength and memory formation. In response to more prolonged stress, a delayed inhibition of hippocampal function develops, which can be attributed to compensatory cellular responses which protect hippocampal neurons from excitotoxicity. The inhibition of hippocampal functioning in response to prolonged stress is potentially relevant to the well-described curvilinear (hormetic) dose-response relationship between arousal and memory. In summary, our emphasis on the temporal features of stress-brain interactions addresses how stress can activate, as well as impair, hippocampal functioning to produce differently shaped (nonhormetic/hormetic) stress-memory dose response functions.
\end{abstract}

Key words: Hippocampus, amygdala, stress, memory, dose-response, corticosterone

\section{INTRODUCTION}

The relationship between stress and memory appears paradoxical. On the one hand, stress can enhance learning and produce powerful memories that last a lifetime, while on the other hand, stress can impair learning and lead to profound memory impairments. A major challenge that faces investigators in the field of stress-memory interactions is to explain the cellular and molecular mechanisms by which such a complex relationship between stress and memory exists. One possible explanation is that the effects of stress on brain memory systems can follow either a hormetic (biphasic) or non-hormetic (threshold, linear) dose-response pattern ${ }^{[1]}$. That is, low levels or brief periods of stress stimulate and enhance memory mechanisms, while high levels or prolonged periods of stress may either inhibit or enhance brain mechanisms underlying synaptic plasticity. Hormetic dose-response functions have been well documented in toxicology research, where a number of chemical substances that have harmful, toxic effects at high doses (e.g., arsenic, alcohol) can produce decidedly non-toxic and even beneficial, effects at low doses ${ }^{[2]}$. In the current review, we will discuss how stress interacts with learning to either enhance or impair memory and how the relationship between the amount of stress and its effects on cognitive processes depends on the interactions of factors related to the stressor, the learning experience and the brain memory systems activated by the learning experience.

Corresponding Author: David M. Diamond, Department of Psychology, PCD 4118G, University of South Florida, Tampa, FL, 33620 Tel: 813-974-0480 Fax: 813-974-4617 


\section{THE PHYSIOLOGY OF STRESS}

It is essential for stressors to rapidly activate physiological systems which enable an individual to survive a threat to its survival. To accomplish this goal, stressors activate two primary physiological systems, the sympathetic-adrenomedullary system and the hypothalamus-pituitary-adrenal (HPA) axis. Activation of the sympathetic-adrenomedullary system leads to a rapid, almost immediate, release of epinephrine and norepinephrine from the adrenal medulla, which mobilizes metabolic resources that are necessary for the fight-or-flight response ${ }^{[3]}$. Activation of the HPA axis, on the other hand, is a slower response that eventually, minutes later, leads to the release of corticosteroids from the adrenal cortex ${ }^{[4,5]}$. An important function of corticosteroids is to act as a homeostatic mechanism and to regulate the stress response. Corticosteroids do so by exerting negative feedback inhibition on brain structures involved in the HPA axis and by inhibiting sympathetic nervous system activity ${ }^{[6-8]}$. Thus, the sympathetic-adrenomedullary system, in addition to precursor hormones of the HPA axis (i.e., corticotropinreleasing hormone and adrenocorticotropic hormone), generate the stress response and prepare an individual for action, and the primary purpose of corticosteroids is to restore homeostasis to an activated physiological system.

Nearly four decades ago, Bruce McEwen and colleagues reported that the hippocampus, a medial temporal lobe structure that plays a significant role in declarative memory in humans ${ }^{[9-11]}$ and spatial working memory in rodents ${ }^{[12-17]}$, contains a greater density of corticosteroid receptors than any other brain region, making it highly sensitive to stress ${ }^{[18-20]}$. One reason why the hippocampus contains such a high density of corticosteroid receptors is because it plays an important role in the negative feedback regulation of the HPA axis. Thus, studies have shown that hippocampal lesions result in significantly greater baseline and stress-evoked levels of corticosteroids ${ }^{[21-23]}$. There are two types of corticosteroid receptors, both of which are widely distributed throughout the hippocampus ${ }^{[5,24,25]}$. One type is the mineralocorticoid receptor (MR), which has a high affinity for corticosteroids and is thus almost fully saturated under baseline physiological conditions. The second type is the glucocorticoid receptor (GR), which has one-tenth the affinity for corticosteroids as the MR and becomes extensively occupied only when there is a large increase in circulating levels of corticosteroids, as occurs during stress. Most MRs and GRs are located in intracellularly and when bound by corticosteroids, act as nuclear transcription factors to alter gene expression. However, recent work has indicated that corticosteroids can also bind to membrane-bound receptors and exert nongenomic effects on cellular activity ${ }^{[26,27]}$. As we will discuss further in subsequent sections, these nongenomic effects have become increasingly important in our understanding of the cellular and molecular mechanisms by which stress affects learning and memory.

\section{WHAT YERKES AND DODSON ACTUALLY FOUND IN THEIR 1908 STUDY ON STRESS AND LEARNING}

Numerous papers in the field of stress-memory interactions have described an inverted U-shaped relationship between stress, or physiological markers of stress (e.g., corticosteroids), and learning ${ }^{[28-32]}$. These descriptions have been based on studies reporting that moderate increases in stress or corticosteroids seem to improve learning and memory, while too little or too much stress or corticosteroids impair these processes. Many investigators reporting a curvilinear relationship between stress and learning have interpreted their findings to conform to the well-known, but misunderstood, Yerkes-Dodson Law ${ }^{[31]}$. However, neither the Yerkes-Dodson Law nor the relationship between stress and learning is characterized by a monolithic, inverted U-shaped function. One century ago, Yerkes and Dodson examined the effects of a range of shock intensities on the rate of learning a discrimination avoidance task in mice ${ }^{[33]}$. These investigators found that when mice were trained to avoid shock in a simple (i.e., black/white) visual discrimination task, their rate of learning increased linearly as the intensity of the shock increased. In contrast, when the mice were trained to avoid shock in a more difficult (i.e., black/gray) visual discrimination task, their rate of learning was optimal under conditions of an intermediate amount of shock, while the lowest and highest levels of shock led to significantly reduced rates of learning. The former finding - that is, the relationship between stress and learning in an easy task, is illustrated in Curve A of Fig. 1, which shows that as stress increases, performance also increases. At extremely high levels of stress, this relationship would theoretically reach an asymptote, at which point performance could no longer be enhanced. The latter finding - that is, the curvilinear relationship between stress and learning in a difficult task, is illustrated in Curve B of Fig. 1, which shows that low and high levels of stress result in weak performance, while 


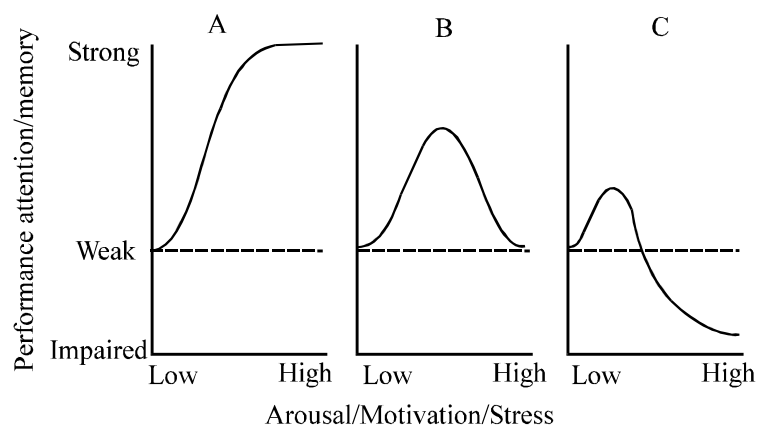

Fig. 1: Linear, inverted U-shaped and hormetic relationships between emotional states (arousal, motivation or stress) and measures of performance (e.g., attention or memory). The curve in (A) depicts a threshold function in which increasing emotionality produces an increase in performance to a maximum (asymptotic) level. The curve in (B) is an inverted-U function in which performance improves, but then deteriorates to baseline, with increasing levels of emotionality. The third curve in (C) depicts a true hormetic doseresponse function between performance and emotionality. In this case, a small increase in arousal or stress produces an improvement of performance, but high levels of emotionality produce a significant impairment of performance below baseline (low stress) levels.

intermediate levels of stress produce optimal performance. These two curves define the true YerkesDodson Law, which illustrates that there is a linear relationship between stress and learning on easy tasks and an inverted U-shaped relationship between stress and learning on difficult tasks (see ${ }^{[31]}$ for related discussion).

Since the original findings of Yerkes and Dodson, numerous studies have demonstrated the importance of task difficulty in mediating the effects of stress and arousal on performance ${ }^{[34-41]}$. That is, investigators have clearly shown that at least two different curves, one linear and the other curvilinear, characterize the relationship between stress and learning, depending on the type of learning experience that occurs ${ }^{[30,31,42]}$. Despite these findings, investigators have largely ignored the linear, task difficulty-based component of the Yerkes-Dodson Law and tend to characterize the relationship between stress and learning as one that is solely curvilinear ${ }^{[43-48]}$. Hence, when a curvilinear relationship has been observed between stress or corticosteroid levels and learning, the finding has been claimed to be consistent with the Yerkes Dodson Law. For instance Andreano and Cahill recently reported an inverted-U relationship between corticosteroid levels at the time of learning and subsequent memory performance ${ }^{[49]}$. The investigators discussed these results by stating, "This finding is consistent with the proposal, first made by Yerkes and Dodson, that there exists an inverted-U relationship between stress and performance - in our case, between endogenous cortisol and memory consolidation" (p. 469). This is an example of how the erroneous and simplified version of what Yerkes and Dodson had originally observed influences cognitive psychologists and behavioral neuroscientists to this day.

The origin of the misrepresentation of the YerkesDodson Law appears to be attributable to work by Donald Hebb ${ }^{[50]}$, among other cognitive psychologists $^{[51,52]}$, in the 1950s. Hebb depicted the relationship between arousal and performance as a curvilinear, inverted U-shaped function. It is perhaps ironic that Hebb's version of the relation between arousal and behavioral performance was not only incomplete, but without even citing the Yerkes and Dodson publication, his description of the curvilinear relation between arousal and performance became synonymous with the Yerkes-Dodson Law. With few exceptions ${ }^{[53,54]}$, researchers who followed $\mathrm{Hebb}^{[55]}$, as well as introductory Psychology textbooks ${ }^{[56]}$, further promulgated the incorrect Hebbian version of the Yerkes-Dodson Law as a single U-shaped curve. It would appear that most contemporary researchers who cite the Yerkes-Dodson Law have failed to read the 1908 paper by Yerkes and Dodson, rendering it one of the most well-cited, but largely unread, papers in the history of science.

\section{WHAT IS THE SHAPE OF THE DOSE-RESPONSE FUNCTION BETWEEN STRESS AND LEARNING?}

Research has shown that, as Yerkes and Dodson originally described, the effects of stress on learning depend upon the interaction of factors related to the stressor, the learning experience and the subject under investigation $^{[29,30,57,58]}$. For example, acute periods of stress or elevations of corticosteroids may have effects on hippocampus-dependent learning and memory, while leaving hippocampus-independent learning and memory, such as reference (long-term) memory, unaffected $^{[41,59-61]}$. With regards to hippocampusdependent tasks, investigators have reported an inverted U-shaped relationship between stress and learning. In human and rodent work, acute stress (or corticosteroid 
administration) dose-dependently influences declarative (conscious, fact-based) and spatial memory, with short periods of stress (or low doses of corticosteroids) enhancing $^{[31,62,63]}$ and longer periods of stress (or high doses of corticosteroids) impairing ${ }^{[59,63-68]}$ these processes. Studies in humans and rodents have shown that exposure to laboratory stressors (humans: preparation and delivery of a speech, mental arithmetic, cold pressor test; rodents: restraint + tailshock, predator exposure, underwater trauma) of a prolonged duration (typically $\geq 20 \mathrm{~min}$ ) before or after learning can impair the recall of information. On the other hand, brief periods of stress (typically $<5 \mathrm{~min}$ ) before or after learning can enhance the recall of information. Importantly, this enhancement of memory is dependent on the temporal proximity of the stressor to the learning experience. Brief periods of stress can enhance the consolidation of hippocampus-dependent memories if they are administered immediately prior to or after learning, but stress may have no effect on or, in some cases, impair long-term memory if there is a substantial delay between the initiation of the stressor and learning. These findings are consistent with the suggestion by Joels and colleagues ${ }^{[29]}$ that the stressor and learning experience must converge in time for the stress to enhance memory.

Joels and coworkers proposed that, to enhance learning, the stressor must not only occur around the time of the learning experience, but also in the context of the learning experience ${ }^{[29]}$. They suggested that, "...stress will only facilitate learning and memory processes: (i) when stress is experienced in the context and around the time of the event that needs to be remembered" (p. 154). Indeed, the ability of stress to facilitate learning when it occurs in the context of the learning experience is clearly evident by the existence of flashbulb memories. Such memories are characterized by an unexpected and evocative event enhancing the storage of neutral, otherwise forgettable, information $^{[69]}$. These memories, such as those regarding the terrorist attacks on September 11, 2001, are so strong that they can last a lifetime and, in some cases, can become pathological, as is found in traumatized people with post-traumatic stress disorder (PTSD). In the case of flashbulb memories, the stressor fulfills both of the criteria set forth by Joels and colleagues $^{[29]}$ - that is, the stressor enhances memory when it occurs closely in time and in the context of the explicit learning experience.

Researchers studying stress-memory interactions have differentiated between the effects of extrinsic stressors and intrinsic stressors on learning ${ }^{[29,30]}$.
Extrinsic stressors are stressors that are outside the context of the learning experience, while intrinsic stressors are a component of the explicit learning experience. Although intrinsic stress is typically beneficial to learning and enhances long-term memory, it can also have deleterious effects on cognition if present for a long enough duration and at a large enough magnitude ${ }^{[30]}$. For instance, although people who experience trauma, such as rape or wartime combat, often have vivid, detailed memories for various aspects of the event, there are some cases in which these individuals develop traumatic amnesia for certain parts of, or even the entire, traumatic incident ${ }^{[70,71]}$. In rodent work, investigators have manipulated the water temperature in the water maze to examine the influence of intrinsic stress on spatial learning. The results of these manipulations have shown that rats trained in relatively cold (i.e., $19^{\circ} \mathrm{C}$ ) water exhibited greater corticosteroid levels (suggestive of a greater stress response) and better memory than rats trained in warmer (i.e., $25^{\circ} \mathrm{C}$ ) water ${ }^{[72]}$. However, rats trained in extremely cold water $\left(12^{\circ} \mathrm{C}\right)$ demonstrated impaired memory, suggesting an overall inverted U-shaped relationship between the intrinsic stressfulness of the task and spatial memory ${ }^{[73]}$. Thus, although intrinsic stress can be beneficial to learning, it can have adverse effects on these processes as well.

Joels and colleagues proposed that stressors which are outside the context of another learning experience (i.e., extrinsic stressors) can enhance memory as long as the stressor is in close temporal and spatial proximity to the learning experience. That is, an animal would remember where it was when it was attacked by a predator, or people would remember where they were when they learned of a national tragedy. In each case, the stress experience overlays in time and space with otherwise neutral information (e.g., where the individuals were when the stressful experience occurred). But is it necessary for both space and time to overlap for an animal to generate a flashbulb memory? Can stress occurring in one environment enhance memory for events occurring in another environment? We tested this possibility in recent work in which rats were stressed in one environment (in a room with cats predator stress) ${ }^{[74-77]}$, and then they were given water maze training in another room. We found that brief (2min) cat exposure administered just prior to water maze training, which occurred in another environment, enhanced the long-term (24-hr) spatial memory of the rats. The enhancement of spatial memory occurred only when cat exposure occurred immediately before training and not when 2 minutes of cat exposure 
occurred 30 minutes before water maze training ${ }^{[31,64]}$. This finding indicates that the brief stress experience had to occur close in time to, but not in the same environment as, the learning experience to enhance memory consolidation.

We would suggest that the stress-induced enhancement of memory, as is found in flashbulb memories and in the cat stress-induced enhancement of spatial memory, follows a linear dose-response function. Thus, the magnitude of the stress-induced enhancement of a simple learning experience increases linearly as the stressor intensity and corticosteroid levels increase ${ }^{[78,79]}$ (Curve A in Fig. 1). For more complex learning tasks, especially those that involve great cognitive demands which require prefrontal cortex activity $^{[80-82]}$, high levels of stress would interfere with performance (Curve B in Fig. 1).

The third graph in Fig. 1, Curve C, represents a true hormetic relationship between stress and learning, in which low levels of stress stimulate and high levels of stress impair cognitive processes. This curve indicates that subjects under a minimal amount of stress (or motivation) exhibit a relatively weak level of performance. From this low motivational level, increasing levels of stress can facilitate performance, and importantly, high levels of stress actually produce performance that is significantly impaired. In a classroom setting, for example, Curve C illustrates 3 conditions: the left side illustrates performance by a student with a low level of motivation and poor performance; the increased level of performance reflects increased motivation and improved performance; and, the reduction in performance at the right side of the curve reflects classical test anxiety. This hormetic curve was actually the topic of Hebb's description of the U-shaped relation between arousal and performance and is what researchers typically consider to be a Yerkes-Dodson Law relationship between stress and performance.

The three different dose-response functions describing the relationship between arousal and performance may be related to the model of stresshippocampus interactions which we described recently ${ }^{[31]}$. In this model, we suggested that stress has an initial stimulatory effect on memory-related functioning of the hippocampus. This rapid and shortlived activation of the hippocampus may underlie the linear dose-response relationship between stress and memory. That is, for rapid memory processing, increases in arousal or stress produce corresponding increases in memory functions of the hippocampus. The enhancement of hippocampal functioning is followed within minutes of the stress onset by an inhibitory effect on hippocampal functioning. New learning occurring during this inhibitory or refractory phase of hippocampal functioning would result in an impairment of memory formation ${ }^{[31]}$. This hypothesis is consistent with the finding that brief periods of stress enhance the acquisition and consolidation of hippocampusdependent memories, but only if they are administered immediately prior to or after learning. If there is a substantial delay between the stress and learning, then long-term memory is not enhanced and, in some cases, is actually impaired. Additionally, this model suggests that even a brief stressor of a large enough magnitude could, after some delay, lead to an inhibition of hippocampal function. Overall, exposure to a brief, intense stressor immediately prior to or following training facilitates the consolidation of information, while exposure to a prolonged stressor immediately prior to training can impair the consolidation of information.

\section{EFFECTS OF STRESS ON HIPPOCAMPAL SYNAPTIC PLASTICITY}

Extensive work has shown that acute stress and the administration of corticosteroids impair the induction of long-term potentiation (LTP) in the hippocampus ${ }^{[31,57,83-86]}$. LTP is an enhancement of synaptic efficacy that results from the high-frequency stimulation of afferent fibers ${ }^{[87,88]}$. It is considered a physiological model of learning and memory because it occurs rapidly, demonstrates longevity, requires cooperativity, is strengthened by repetition and demonstrates associativity and input specificity ${ }^{[87,88]}$. It occurs prominently in the hippocampus; and, pharmacological agents that facilitate the induction of hippocampal LTP enhance learning and memory, whereas pharmacological agents that inhibit the induction of hippocampal LTP impair learning and memory ${ }^{[89,90]}$. Since LTP is an appealing candidate for the biological basis of memory formation, it provides researchers with a means to indirectly assess the effects of stress on learning at the physiological level. In 1987, Thompson and coworkers found that exposing rats to 30 minutes of restraint or restraint combined with tailshock blocked the induction of LTP in CA1 in $v_{\text {vitro }}{ }^{[91]}$. Diamond and colleagues then extended these findings to show that acute stress (exposure to a novel environment) blocked the induction of primed burst potentiation (PBP), a low threshold form of LTP, in the behaving rat ${ }^{[92]}$. Since then, investigators have reported that exposing rodents to a variety of stressors, including 
predators, predator scent, restraint, tailshock, elevated platform stress and a novel environment, impair the induction of hippocampal LTP and PBP in vitro and in vivo $^{[31,57,83-85]}$. The stress effects on LTP are not shortlived, as the stress-induced impairment of hippocampal LTP has been observed up to 48 hours post-stress ${ }^{[93]}$.

Researchers have contended that LTP, alone, cannot provide a sufficient physiological model of learning. In theory, there must be a mechanism by which synaptic efficacy can be actively reduced, as well as enhanced, in order to explain how potentiated synapses could return to baseline and be involved in the storage of additional memories. Such a form of synaptic plasticity, referred to as long-term depression (LTD), has been well demonstrated in the hippocampus and typically results from low-frequency, rather than highfrequency, stimulation of afferent fibers ${ }^{[94]}$. Interestingly, LTP and LTD have the opposite effects on synaptic efficacy, but both are dependent, to a large extent, on similar cellular and molecular mechanisms that is, both involve NMDA receptor activity and $\mathrm{Ca}^{2+}$ dependent intracellular signaling (however, note that multiple forms of both LTP and LTD exist, with each potentially involving different cellular and molecular mechanisms $)^{[87,88,94]}$. In contrast to their effects on hippocampal LTP, acute episodes of stress have been shown to facilitate the induction of $\mathrm{LTD}^{[95-100]}$, which is involved in the stress-induced impairment of hippocampus-dependent memory ${ }^{[101]}$. Researchers have theorized that acute stress activates mechanisms in common with hippocampal $\operatorname{LTP}^{[83,92,102]}$, which then causes subsequent synaptic changes to favor depression (i.e., LTD) rather than potentiation ${ }^{[103]}$.

Importantly, in studies reporting a stress-induced impairment of hippocampal LTP and a stress-induced enhancement of hippocampal LTD, the animals were exposed to a relatively long (at least $30 \mathrm{~min}$ ) stress experience before high-frequency stimulation was delivered to the hippocampus. Our temporal dynamics model, which states that the hippocampus is initially activated and then suppressed by stress ${ }^{[31]}$, predicts that when an emotionally arousing experience occurs in close proximity to the delivery of high-frequency stimulation, the duration of hippocampal LTP should be enhanced. This prediction has been supported by the findings of numerous studies over the past decade ${ }^{[104-110]}$.

The mechanisms involved in the stress-induced modulation of memory and LTP involve the rapid release of epinephrine and norepinephrine from the adrenal medulla, which facilitates the mobilization of metabolic resources that are necessary for the fight-orflight response. Numerous studies have reported that the administration of epinephrine before or after learning enhances hippocampus-dependent memory ${ }^{[111-118]}$. Similar to the stress-induced enhancement of learning, this effect is temporallyrestricted - that is, as the delay between epinephrine administration and learning increases, the epinephrineinduced enhancement of learning decreases ${ }^{[116]}$. In addition, epinephrine enhances hippocampal $\operatorname{LTP}^{[119]}$, while adrenal demedullation impairs hippocampal $\mathrm{LTP}^{[120]}$. Research has suggested that the enhancing effects of epinephrine are due to $\beta$-adrenergic receptor activity, as the administration of $\beta$-adrenergic receptor antagonists blocks the epinephrine-induced enhancement of hippocampal function ${ }^{[113,121]}$ and the administration of $\beta$-adrenergic receptor agonists facilitates hippocampal function ${ }^{[122-124]}$.

When Thompson and colleagues first reported that acute stress impaired hippocampal synaptic plasticity, they also noted a significant negative relationship between corticosteroid levels and inducible $\mathrm{LTP}^{[91]}$. Since then, several studies have reported that the administration of corticosteroids can impair hippocampus-dependent learning and memory and hippocampal LTP in vivo and in vitro ${ }^{[5,58,125]}$. However, a complete removal (via adrenalectomy) or significant reduction (via metyrapone, a pharmacological inhibitor of corticosteroid synthesis) of circulating corticosteroids also leads to impairments of hippocampus-dependent learning and memory, as well as hippocampal synaptic plasticity, suggesting an inverted U-shaped dose-response relationship between corticosteroids and hippocampal function ${ }^{[5,58,125]}$.

In one study, Diamond and colleagues found that at low levels of circulating corticosteroids (i.e., 0-20 $\mu \mathrm{g} / \mathrm{dL})$, there was a positive relationship between corticosteroids and hippocampal PBP, while at elevated levels (i.e. stress levels, or $>20 \mu \mathrm{g} / \mathrm{dL}$ ), this relationship was negative ${ }^{[126]}$. The investigators also reported that extremely high levels of corticosteroids (i.e., > 60 $\mu \mathrm{g} / \mathrm{dL})$ promoted synaptic depression. Such findings suggested that there was a hormetic, rather than a simple inverted U-shaped, dose-response relationship between corticosteroids and hippocampal synaptic plasticity. Although adrenalectomy, which resulted in almost a complete absence of circulating corticosteroids, impaired synaptic potentiation, it did not result in the facilitation of synaptic depression. Such a response was only observed in the presence of extremely high circulating levels of corticosteroids. Thus, this work suggested that moderate increases in corticosteroids facilitate hippocampal plasticity, while extreme increases in corticosteroids have deleterious effects on hippocampal synaptic plasticity. 
These findings coincide with research in humans examining the effects of corticosteroid administration on learning. For instance, when investigators gave participants hydrocortisone prior to learning in the morning hours (when cortisol levels are at their peak in humans), subjects exhibited impaired memory for the information at test ${ }^{[127]}$. On the other hand, if the hydrocortisone was given prior to learning in the afternoon hours (when cortisol levels are relatively low in humans), the subjects demonstrated enhanced performance at test ${ }^{[128]}$. In theory, the administration of hydrocortisone in the morning hours, when endogenous corticosteroid levels were at the peak of Curve B in Fig. 1, drove corticosteroid levels to the right part of Curve B, which resulted in impaired performance. In contrast, the administration of hydrocortisone in the afternoon hours, when endogenous corticosteroid levels were low and at the left portion of Curve B in Fig. 1, thrust corticosteroid levels to the peak of Curve B, which led to enhanced performance. Collectively, these findings suggest that the inverted U-shaped relationship between stress and hippocampus-dependent learning and memory may be a result of corticosteroid activity.

According to the Opposing Receptor Hypothesis, activation of MRs is responsible for the corticosteroidinduced enhancement of hippocampal plasticity, while the activation of GRs is responsible for the corticosteroid-induced impairment of hippocampal plasticity $^{[129]}$. This opposing role of MRs and GRs in hippocampal plasticity is based on the fact that low levels of circulating corticosteroids result in MR activation, while higher levels of circulating corticosteroids, such as those observed during stress, result in GR activation ${ }^{[4,5]}$. This hypothesis was initially supported by replacement studies reporting that, in adrenalectomized rats, the administration of the MR agonist aldosterone enhanced hippocampal LTP and rescued spatial memory impairment ${ }^{[130,131]}$, while the administration of GR agonists impaired hippocampal LTP and enhanced hippocampal LTD ${ }^{[130-132]}$. However, as Conrad and colleagues ${ }^{[129]}$ pointed out, studies examining the effects of corticosteroid receptor antagonists on hippocampal function in intact rats (i.e., subtractive studies) did not support the Opposing Receptor Hypothesis. Indeed, the administration of GR antagonists led to impaired spatial memory, while the administration of MR antagonists had no observable effect on these processes ${ }^{[133,134]}$.

Further research revealed that some GR occupancy is necessary for optimal hippocampal function. In a series of experiments, Conrad and colleagues found that when GRs were either completely blocked or highly occupied, rats exhibited impaired spatial memory in the Y-maze, an effect that was independent of the level of MR activation ${ }^{[129]}$. In other words, only when there was a moderate level of GR occupancy did rats exhibit intact spatial memory. Collectively, these findings suggested that GR activity may be responsible for mediating the hormetic relationship between corticosteroids and hippocampal function. Moreover, the findings support the notion that during low levels of stress, when there are moderate increases in corticosteroid levels which occupy few GRs, hippocampal synaptic plasticity and hippocampusdependent learning and memory are enhanced, while during high levels of stress, when there are significant elevations of corticosteroid levels and almost a complete saturation of GRs, hippocampal synaptic plasticity and hippocampus-dependent learning and memory are impaired.

As indicated above, corticosteroids typically exert their effects on cells by binding to intracellular receptors, which then enter the nucleus and act as transcription factors to modulate gene expression ${ }^{[28]}$. More recent work has indicated that corticosteroids can also bind to membrane-bound receptors and exert rapid, nongenomic effects on neuronal transmission. For instance, systemic administration of corticosterone in rats leads to a rapid (e.g., < $15 \mathrm{~min}$ ) increase in extracellular levels of the excitatory amino acids glutamate and aspartate in the CA1 region of the hippocampus, an effect that is still observed following the administration of selective intracellular corticosteroid receptor antagonists ${ }^{[135]}$. Additional work has shown that bath application of corticosteroids enhances the frequency of miniature excitatory postsynaptic currents in CA1 hippocampal neurons within 5-10 minutes ${ }^{[26]}$. This effect was shown to be mediated by an MR-dependent increase in glutamate transmission. Interestingly, the threshold corticosteroid concentration for these rapid nongenomic effects is 10to 20-fold greater than in vitro effects observed on intracellular MRs. Such a finding could explain how stress can have an immediate excitatory effect on hippocampal synaptic plasticity and, consequentially, learning and memory. As explained by Karst et $\mathrm{al}^{[26]}$ :

The requirement of at least $10 \mathrm{nM}$ corticosterone to induce rapid effects on hippocampal glutamate transmission indicates that such effects will not occur with basal levels of the hormone but only when hormone levels are elevated...This mechanism would supply the brain with the means to react quickly to stress through the MR, next to other rapid stressactivated systems involving noradrenaline and corticotropin-releasing hormone (p. 19207). 
The nongenomic effect of corticosteroids on hippocampal function could explain how an intense episode of brief stress rapidly facilitates hippocampusdependent learning and memory and aids in the formation of flashbulb memories (Fig. 1 A). As indicated above, the corticosteroids rapidly increase glutamate transmission in the hippocampus, which would foster optimal conditions for synaptic plasticity and learning to occur. However, this corticosteroidinduced enhancement of glutamatergic transmission in the hippocampus would also trigger processes that inevitably lead to a decrease in hippocampal function and impaired learning and memory (Fig. 1 B, C). As glutamate transmission is persistently enhanced by corticosteroids, calcium would continue to enter hippocampal cells ${ }^{[5,136,137]}$. This would cause NMDA receptors in the hippocampus to desensitize in order to protect the cells from excitotoxicity ${ }^{[138-142]}$. Although this is an advantageous mechanism to shelter the cells from damage, it would theoretically lead to impaired synaptic plasticity and learning.

\section{INTEGRATIVE NETWORK APPROACH TO THE CELLULAR AND MOLECULAR MECHANISMS UNDERLYING HORMETIC AND NON-HORMETIC RELATIONSHIPS BETWEEN STRESS AND LEARNING}

An acute stress experience promotes the massive release of several neuromodulators (e.g., glutamate, acetylcholine, dopamine, corticotropin-releasing hormone, norepinephrine), which ultimately lead to enhanced learning and memory and activates endogenous forms of neuroplasticity in the hippocampus ${ }^{[106,110,124,143-154]}$. Corticosteroid-mediated effects on the hippocampus would not be observed immediately with the onset of the stress, as there is at least a several minute delay from the onset of stress and the release of corticosteroids from the adrenal cortex. When the corticosteroids reached the hippocampus, they would exert an immediate nongenomic, MRdependent excitatory effect on learning and memory mechanisms. This excitatory effect of corticosterone would interact with increased glutamatergic transmission and activate intracellular calciumdependent signaling cascades. At the same time, stress would activate cellular processes within the amygdala, which would also lead to a direct enhancement of hippocampal plasticity. Collectively, all of these stimulatory mechanisms would facilitate the storage of information occurring at the time of stress onset, enabling the formation of flashbulb memories.
However, as the stressor continued and corticosteroid levels steadily rose, a massive buildup of postsynaptic glutamate and calcium, as well as extensive GR activation, would ensue, promoting the desensitization of NMDA receptors and impaired hippocampal function. This stress-induced refractory period would lead to impaired synaptic plasticity within the hippocampus and, consequently, impaired learning and memory.

It is important to note that the hormesis-like relationship between stress and learning undoubtedly varies depending on the context in which the stress and learning occur. For instance, the type and duration of stressor, as well as several characteristics of the task itself (e.g., difficulty, aversiveness), would likely modulate the height and width of the peak and nadir of Curve $\mathrm{C}$ in Figure 1. In addition, although prolonged periods of acute stress may lead to impaired hippocampal function, they do not completely incapacitate the subject under investigation. Indeed, some tasks, such as contextual fear conditioning, are likely to remain unaffected following prolonged periods of stress, especially when these tasks retain important survival information. The cognitive abilities that remain unaffected in such periods of stress are likely to be explained by the fact that some forms of synaptic plasticity are not impaired and may actually be enhanced, by prolonged stress (e.g., voltage-gated calcium channel-dependent LTP ${ }^{[86]}$.

\section{SUMMARY}

For over a century, researchers have described the complex relationship between stress and behavioral performance. Depending on the interaction of numerous factors, stress may enhance, impair or have no effect on learning and memory. We have discussed the behavioral and neurobiological basis of these findings in a format which represents stress-memory interactions as conforming to linear (threshold), U-shaped or hormetic dose-response functions. We have also discussed how the expression of stress-memory interactions is influenced by the brain structures (prefrontal cortex, hippocampus and amygdala) that are involved in the processing of the information, which interact with the relative timing of cues, such as when a stressful experience influences the storage of otherwise neutral information storage, as occurs with traumatic and flashbulb memories. Our approach to integrate multiple dose-response functions with synaptic plasticity underlying memory storage may provide a structure with which to improve our understanding of 
how strong emotionality exerts such powerful positive, as well as negative, effects on memory.

\section{REFERENCES}

1. Calabrese, E.J. and L.A. Baldwin, 2002. Defining hormesis. Hum. Exp. Toxicol., 21: 91-97.

2. Calabrese, E.J., L.A. Baldwin and C.D. Holland, 1999. Hormesis: A highly generalizable and reproducible phenomenon with important implications for risk assessment. Risk Anal., 19: 261-281.

3. Gunnar, M. and K. Quevedo, 2007. The neurobiology of stress and development. Ann. Rev. Psychol., 58: 145-173.

4. de Kloet, E.R., M.S. Oitzl and M. Joels, 1999. Stress and cognition: Are corticosteroids good or bad guys? Trends Neurosci., 22: 422-426.

5. Joels, M., 2001. Corticosteroid actions in the hippocampus. J. Neuroendocrinol., 13: 657-669.

6. Brown, M.R. and L.A. Fisher, 1986. Glucocorticoid suppression of the sympathetic nervous system and adrenal medulla. Life Sci., 39: 1003-1012.

7. Komesaroff, P.A. and J.W. Funder, 1994. Differential glucocorticoid effects on catecholamine responses to stress. Am. J. Physiol, 266: E118-E128.

8. Kvetnansky, R., K. Fukuhara, K. Pacak, G. Cizza, D.S. Goldstein and I.J. Kopin, 1993. Endogenous glucocorticoids restrain catecholamine synthesis and release at rest and during immobilization stress in rats. Endocrinology, 133: 1411-1419.

9. Eichenbaum, H., 2006. Remembering: functional organization of the declarative memory system. Curr. Biol., 16: R643-R645.

10. Squire, L.R., C.E. Stark and R.E. Clark, 2004. The medial temporal lobe. Ann. Rev. Neurosci., 27: 279-306.

11. Eichenbaum, H., 2004. Hippocampus: cognitive processes and neural representations that underlie declarative memory. Neuron, 44: 109-120.

12. Moser, M.B. and E.I. Moser, 1998. Distributed encoding and retrieval of spatial memory in the hippocampus. J. Neurosci., 18: 7535-7542.

13. Winocur, G., M. Moscovitch, D.A. Caruana and M.A. Binns, 2005. Retrograde amnesia in rats with lesions to the hippocampus on a test of spatial memory. Neuropsychologia, 43: 1580-1590.

14. Moses, S.N., C. Cole and J.D. Ryan, 2005. Relational memory for object identity and spatial location in rats with lesions of perirhinal cortex, amygdala and hippocampus. Brain Res. Bull., 65: 501-512.
15. Broadbent, N.J., L.R. Squire and R.E. Clark, 2004. Spatial memory, recognition memory and the hippocampus. Proc. Natl. Acad. Sci. U.S.A, 101: 14515-14520.

16. Broadbent, N.J., L.R. Squire and R.E. Clark, 2006. Reversible hippocampal lesions disrupt water maze performance during both recent and remote memory tests. Learn. Mem., 13: 187-191.

17. Kaut, K.P. and M.D. Bunsey, 2001. The effects of lesions to the rat hippocampus or rhinal cortex on olfactory and spatial memory: Retrograde and anterograde findings. Cogn Affect. Behav. Neurosci., 1: 270-86.

18. McEwen, B.S., J.M. Weiss and L.S. Schwartz, 1969. Uptake of corticosterone by rat brain and its concentration by certain limbic structures. Brain Res., 16: 227-241.

19. McEwen, B.S. and J.M. Weiss, 1970. The uptake and action of corticosterone: Regional and subcellular studies on rat brain. Prog. Brain Res., 32: 200-212.

20. McEwen, B.S., J.M. Weiss and L.S. Schwartz, 1968. Selective retention of corticosterone by limbic structures in rat brain. Nature, 220: 911-912.

21. Sapolsky, R.M., L.C. Krey and B.S. McEwen, 1984. Glucocorticoid-sensitive hippocampal neurons are involved in terminating the adrenocortical stress response. Proc. Natl. Acad. Sci. U. S. A, 81: 6174-6177.

22. Wilson, M.M., S.E. Greer, M.A. Greer and L. Roberts, 1980. Hippocampal inhibition of pituitary-adrenocortical function in female rats. Brain Res., 197: 433-441.

23. Herman, J.P., M.K. Schafer, E.A. Young, R. Thompson, J. Douglass, H. Akil and S.J. Watson, 1989. Evidence for hippocampal regulation of neuroendocrine neurons of the hypothalamo-pituitary-adrenocortical axis. J. Neurosci., 9: 3072-3082.

24. McEwen, B.S., H. Cameron, H.M. Chao, E. Gould, V. Luine, A.M. Magarinos, C. Pavlides, R.L. Spencer, Y. Watanabe and C. Woolley, 1994. Resolving a mystery: progress in understanding the function of adrenal steroid receptors in hippocampus. Prog. Brain Res., 100: 149-155.

25. de Kloet, E.R., M.S. Oitzl and M. Joels, 1999. Stress and cognition: are corticosteroids good or bad guys? Trends Neurosci., 22: 422-426.

26. Karst, H., S. Berger, M. Turiault, F. Tronche, G. Schutz and M. Joels, 2005. Mineralocorticoid receptors are indispensable for nongenomic modulation of hippocampal glutamate transmission by corticosterone. Proc. Natl. Acad. Sci. U. S A, 102: 19204-19207. 
27. Wiegert, O., M. Joels and H. Krugers, 2006. Timing is essential for rapid effects of corticosterone on synaptic potentiation in the mouse hippocampus. Learn. Mem., 13: 110-113.

28. Joels, M., 2006. Corticosteroid effects in the brain: U-shape it. Trends Pharmacol. Sci., 27: 244-250.

29. Joels, M., Z. Pu, O. Wiegert, M.S. Oitzl and H.J. Krugers, 2006. Learning under stress: How does it work? Trends Cogn Sci., 10: 152-158.

30. Sandi, C. and M.T. Pinelo-Nava, 2007. Stress and Memory: Behavioral Effects and Neurobiological Mechanisms. Neural. Plast., 2007: 78970.

31. Diamond, D.M., A.M. Campbell, C.R. Park, J. Halonen and P.R. Zoladz, 2007. The temporal dynamics model of emotional memory processing: a synthesis on the neurobiological basis of stressinduced amnesia, flashbulb and traumatic memories and the Yerkes-Dodson Law. Neural Plast., 60803.

32. Hancock, P.A. and H.C.N. Ganey, 2003. From the inverted- $U$ to the extended- $U$ : the evolution of a law of psychology. Human Performance Extreme Environ., 7: 5-14.

33. Yerkes, R.M. and J.D. Dodson, 1908. The relation of strength of stimulus to rapidity of habitformation. J. Comp. Neurol. Psychol., 18: 459-482.

34. Dickman, S.J., 2002. Dimensions of arousal: Wake Fulness and vigor. Hum. Factors, 44: 429-442.

35. Hammes, J.A., 1956. Visual discrimination learning as a function of shock-fear and task difficulty. J. Comp. Physiol. Psychol., 49: 481-484.

36. Denenberg, V.H. and G.G. Karas, 1960. Supplementary report: The Yerkes-Dodson law and shift in task difficulty. J. Exp. Psychol., 59: 429-30.

37. Telegdy, G.A. and J.S. Cohen, 1971. Cue Utilization and Drive Level in Albino Rat. J. Comp. Physiol. Psychol., 75: 248.

38. Bregman, N.J. and H.A. McAllister, 1982. Motivation and skin temperature biofeedbackyerkes-dodson revisited. Psychophysiology, 19: 282-85.

39. Anderson, K.J., 1994. Impulsivity, caffeine and task-difficulty-A within-subjects test of the yerkesdodson law. Personality Individual Differences, 16: 813-829.

40. Mesches, M.H., M. Fleshner, K.L. Heman, G.M. Rose and D.M. Diamond, 1999. Exposing rats to a predator blocks primed burst potentiation in the hippocampus in vitro. J. Neurosci, 19: RC18.

41. Diamond, D.M., C.R. Park, K.L. Heman and G.M. Rose, 1999. Exposing rats to a predator impairs spatial working memory in the radial arm water maze. Hippocampus, 9: 542-552.
42. Metcalfe, J. and W.J. Jacobs, 1998. Emotional memory: The effects of stress on cool and hot memory systems. Psychol. Learn. Motivat., 38: 187-222.

43. Loftus, E.F., 1980. Memory, Surprising Insights into how we Remember and why we Forget. Addison-Wesley, Reading, Massachusetts.

44. Neiss, R., 1988. Reconceptualizing arousal: Psychobiological states in motor performance. Psychol. Bull., 103: 345-366.

45. Aston-Jones, G., J. Rajkowski and J. Cohen, 1999. Role of locus coeruleus in attention and behavioral flexibility. Biol. Psychiatry, 46: 1309-1320.

46. Mendl, M., 1999. Performing under pressure: stress and cognitive function. Applied Animal Behaviour Science, 65: 221-244.

47. Aston-Jones, G., J. Rajkowski and J. Cohen, 2000. Locus coeruleus and regulation of behavioral flexibility and attention. Prog. Brain Res., 126: $165-182$.

48. Morris, R., 2006. Stress and the hippocampus. In: The Hippocampus Book, Andersen, P., R. Morris, D. Amaral, T. Bliss and J. O'Keefe (Eds.). Oxford, New York. pp: 751-768.

49. Andreano, J.M. and L. Cahill, 2006. Glucocorticoid release and memory consolidation in men and women. Psychol. Sci., 17: 466-470.

50. Hebb, D.O., 1955. Drives and the C.N.S. (conceptual nervous system). Psychol. Rev., 62: 243-254.

51. Schlosberg, H., 1954. Three dimensions of emotion. Psychol. Rev., 61: 81-88.

52. Duffy, E., 1957. The psychological significance of the concept of arousal or activation. Psychol. Rev., 64: 265-275.

53. Teigen, K.H., 1994. Yerkes-dodson-a law for all seasons. Theory Psychol., 4: 525-547.

54. Hanoch, Y. and O. Vitouch, 2004. When less is more-Information, emotional arousal and the ecological reframing of the Yerkes-Dodson law. Theory Psychol., 14: 427-452.

55. Broadbent, D.E., 1965. A Reformulation of the Yerkes-Dodson Law. Br. J. Math. Stat. Psychol., 18: $145-157$.

56. Radvansky, G., 2006. Human Memory. Allyn and Bacon, New York.

57. Kim, J.J., E.Y. Song and T.A. Kosten, 2006. Stress effects in the hippocampus: synaptic plasticity and memory. Stress, 9: 1-11.

58. Lupien, S.J., F. Maheu, M. Tu, A. Fiocco and T.E. Schramek, 2007. The effects of stress and stress hormones on human cognition: Implications for the field of brain and cognition. Brain Cogn., 65: 209-37. 
59. Kirschbaum, C., O.T. Wolf, M. May, W. Wippich and D.H. Hellhammer, 1996. Stress- and treatmentinduced elevations of cortisol levels associated with impaired declarative memory in healthy adults. Life Sci., 58: 1475-1483.

60. Diamond, D.M., M. Fleshner, N. Ingersoll and G.M. Rose, 1996. Psychological stress impairs spatial working memory: Relevance to electrophysiological studies of hippocampal function. Behav. Neurosci., 110: 661-672.

61. Woodson, J.C., D. Macintosh, M. Fleshner and D.M. Diamond, 2003. Emotion-induced amnesia in rats: working memory-specific impairment, corticosterone-memory correlation and fear versus arousal effects on memory. Learn. Mem., 10: 326-336.

62. Cahill, L., L. Gorski and K. Le, 2003. Enhanced human memory consolidation with post-learning stress: interaction with the degree of arousal at encoding. Learn. Mem., 10: 270-274.

63. Lupien, S.J. and B.S. McEwen, 1997. The acute effects of corticosteroids on cognition: Integration of animal and human model studies. Brain Res. Rev., 24: 1-27.

64. Diamond, D.M., A.M. Campbell, C.R. Park, J.C. Woodson, C.D. Conrad, A.D. Bachstetter and R.F. Mervis, 2006. Influence of predator stress on the consolidation versus retrieval of long-term spatial memory and hippocampal spinogenesis. Hippocampus, 16: 571-576.

65. Richter-Levin, G., 1998. Acute and long-term behavioral correlates of underwater traumapotential relevance to stress and post-stress syndromes. Psychiatry Res., 79: 73-83.

66. Elzinga, B.M., A. Bakker and J.D. Bremner, 2005. Stress-induced cortisol elevations are associated with impaired delayed, but not immediate recall. Psychiatry Res., 134: 211-23.

67. Healy, D.J. and R.C. Drugan, 1994. Escapable stress modulates retention of spatial learning in rats: Preliminary evidence for involvement of neurosteroids. Psychobiology, 24: Jun-117.

68. Klenerova, V., V.O. Kaminsky, Si, P. da, Krejci, I.Z. Hlinak and S. Hynie, 2002. Impaired passive avoidance acquisition in Sprague-Dawley and lewis rats after restraint and cold stress. Behav. Brain Res., 136: 21.

69. Brown, R. and J. Kulik, 1977. Flashbulb Memories. Cognition, 5: 73-99.

70. Joseph, R., 1999. The neurology of traumatic dissociative amnesia: Commentary and literature review. Child Abuse Neglect, 23: 715-27.
71. Joseph, R., 1998. Traumatic amnesia, repression and hippocampus injury due to emotional stress, corticosteroids and enkephalins. Child Psychiatry Human Dev., 29: 169-185.

72. Sandi, C., M. Loscertales and C. Guaza, 1997. Experience-dependent facilitating effect of corticosterone on spatial memory formation in the water maze. Eur. J. Neurosci., 9: 637-642.

73. Selden, N.R., B.J. Cole, B.J. Everitt and T.W. Robbins, 1990. Damage to ceruleo-cortical noradrenergic projections impairs locally cued but enhances spatially cued water maze acquisition. Behav. Brain Res., 39: 29-51.

74. Hubbard, D.T., D.C. Blanchard, M. Yang, C.M. Markham, A. Gervacio, I. Chun and R.J. Blanchard, 2004. Development of defensive behavior and conditioning to cat odor in the rat. Physiol. Behav., 80: 525-530.

75. Blanchard, R.J., D.C. Blanchard, J. Rodgers and S.M. Weiss, 1990. The characterization and modeling of antipredator defensive behavior. Neurosci. Biobehav. Rev., 14: 463-472.

76. Blanchard, D.C., N.S. Canteras, C.M. Markham, N.S. Pentkowski and R.J. Blanchard, 2005. Lesions of structures showing FOS expression to cat presentation: Effects on responsivity to a cat, cat odor and nonpredator threat. Neurosci. Biobehav. Rev., 29: 1243-1253.

77. Blanchard, D.C., G. Griebel and R.J. Blanchard, 2003. Conditioning and residual emotionality effects of predator stimuli: some reflections on stress and emotion. Progress NeuroPsychopharmacol. Biol. Psychiatry, 27: 1177-1185.

78. Shors, T.J. and R.J. Servatius, 1997. The contribution of stressor intensity, duration and context to the stress-induced facilitation of associative learning. Neurobiol. Learn. Mem., 68: 92-96.

79. Shors, T.J., 2004. Learning during stressful times. Learn. Mem., 11: 137-144.

80. Tregellas, J.R., D.B. Davalos and D.C. Rojas, 2006. Effect of task difficulty on the functional anatomy of temporal processing. Neuroimage,

81. Bokde, A.L., W. Dong, C. Born, G. Leinsinger, T. Meindl, S.J. Teipel, M. Reiser and H. Hampel, 2005. Task difficulty in a simultaneous face matching task modulates activity in face fusiform area. Brain Res. Cogn Brain Res., 25: 701-710.

82. Elliott, R., S.C. Baker, R.D. Rogers, D.A. O'Leary, E.S. Paykel, C.D. Frith, R.J. Dolan and B.J. Sahakian, 1997. Prefrontal dysfunction in depressed patients performing a complex planning task: A study using positron emission tomography. Psychol. Med., 27: 931-42. 
83. Diamond, D.M., C.R. Park and J.C. Woodson, 2004. Stress generates emotional memories and retrograde amnesia by inducing an endogenous form of hippocampal LTP. Hippocampus, 14: 281-291.

84. Diamond, D.M., C.R. Park, A.M. Campbell and J.C. Woodson, 2005. Competitive interactions between endogenous LTD and LTP in the hippocampus underlie the storage of emotional memories and stress-induced amnesia. Hippocampus, 15: 1006-1025.

85. Kim, J.J. and D.M. Diamond, 2002. The stressed hippocampus, synaptic plasticity and lost memories. Nat. Rev. Neurosci., 3: 453-462.

86. Joels, M. and H.J. Krugers, 2007. LTP after stress: up or down? Neural Plast., 93202.

87. Raymond, C.R., 2007. LTP forms 1, 2 and 3: Different mechanisms for the long in long-term potentiation. Trends Neurosci., 30: 167-175.

88. Citri, A. and R.C. Malenka, 2008. Synaptic plasticity: multiple forms, functions and mechanisms. Neuropsychopharmacol., 33: 18-41.

89. Morris, R.G., E. Anderson, G.S. Lynch and M. Baudry, 1986. Selective impairment of learning and blockade of long-term potentiation by an $\mathrm{N}$ methyl-D-aspartate receptor antagonist, AP5. Nature, 319: 774-776.

90. Martin, S.J., P.D. Grimwood and R.G. Morris, 2000. Synaptic plasticity and memory: An evaluation of the hypothesis. Ann. Rev. Neurosci., 23: 649-711.

91. Foy, M.R., M.E. Stanton, S. Levine and R.F. Thompson, 1987. Behavioral stress impairs long-term potentiation in rodent hippocampus. Behav. Neural Biol., 48: 138-149.

92. Diamond, D.M., M.C. Bennett, K.E. Stevens, R.L. Wilson and G.M. Rose, 1990. Exposure to a novel environment interferes with the induction of hippocampal primed burst potentiation in the behaving rat. Psychobiology, 18: 273-281.

93. Shors, T.J., R.A. Gallegos and A. Breindl, 1997. Transient and persistent consequences of acute stress on long-term potentiation (LTP), synaptic efficacy, theta rhythms and bursts in area CA1 of the hippocampus. Synapse, 26: 209-217.

94. Massey, P.V. and Z.I. Bashir, 2007. Long-term depression: multiple forms and implications for brain function. Trends Neurosci., 30: 176-184.

95. Chaouloff, F., A. Hemar and O. Manzoni, 2007. Acute stress facilitates hippocampal CA1 metabotropic glutamate receptor-dependent longterm depression. J Neurosci., 27: 7130-7135.
96. Kim, J.J., M.R. Foy and R.F. Thompson, 1996. Behavioral stress modifies hippocampal plasticity through N-methyl-D-aspartate receptor activation. Proc. Natl. Acad. Sci. U.S.A, 93: 4750-4753.

97. Xu, L., R. Anwyl and M.J. Rowan, 1997. Behavioural stress facilitates the induction of longterm depression in the hippocampus. Nature, 387: 497-500.

98. Yang, C.H., C.C. Huang and K.S. Hsu, 2005. Behavioral stress enhances hippocampal CA1 longterm depression through the blockade of the glutamate uptake. J. Neurosci., 25: 4288-93.

99. Yang, C.H., C.C. Huang and K.S. Hsu, 2004. Behavioral stress modifies hippocampal synaptic plasticity through corticosterone-induced sustained extracellular signal-regulated kinase/mitogenactivated protein kinase activation. J. Neurosci, 24: 11029-11034.

100.Xu, L., C. Holscher, R. Anwyl and M.J. Rowan, 1998. Glucocorticoid receptor and protein/RNA synthesis-dependent mechanisms underlie the control of synaptic plasticity by stress. Proc. NatL. Acad. Sci. U.S.A., 95: 3204-3208.

101.Wong, T.P., J.G. Howland, J.M. Robillard, Y. Ge, W. Yu, A.K. Titterness, K. Brebner, L. Liu, J. Weinberg, B.R. Christie, A.G. Phillips and Y.T. Wang, 2007. Hippocampal long-term depression mediates acute stress-induced spatial memory retrieval impairment. Proc. Natl. Acad. Sci. U.S.A, 104: 11471-11476.

102.Huang, C.C., C.H. Yang and K.S. Hsu, 2005. Do stress and long-term potentiation share the same molecular mechanisms? Mol. Neurobiol., 32: 223-235.

103.Kim, J.J. and K.S. Yoon, 1998. Stress: Metaplastic effects in the hippocampus. Trends Neurosci, 21: 505-509.

104.Seidenbecher, T., K.G. Reymann and D. Balschun, 1997. A post-tetanic time window for the reinforcement of long-term potentiation by appetitive and aversive stimuli. Proc. Natl. Acad. Sci. U.S.A., 94: 1494-1499.

105.Frey, J.U., 2001. Long-lasting hippocampal plasticity: Cellular model for memory consolidation? Res. Probl. Cell Differ., 34: 27-40.

106.Li, S., W.K. Cullen, R. Anwyl and M.J. Rowan, 2003. Dopamine-dependent facilitation of LTP induction in hippocampal CA1 by exposure to spatial novelty. Nat. Neurosci., 6: 526-531.

107.Straube, T., V. Korz and J.U. Frey, 2003. Bidirectional modulation of long-term potentiation by novelty-exploration in rat dentate gyrus. Neurosci. Lett., 344: 5-8. 
108.Davis, C.D., F.L. Jones and B.E. Derrick, 2004. Novel environments enhance the induction and maintenance of long-term potentiation in the dentate gyrus. J. Neurosci., 24: 6497-6506.

109.Almaguer-Melian, W., R. Cruz-Aguado, C.L. Riva, K.M. Kendrick, J.U. Frey and J. Bergado, 2005. Effect of LTP-reinforcing paradigms on neurotransmitter release in the dentate gyrus of young and aged rats. Biochem. Biophys. Res. Commun., 327: 877-883.

110.Ahmed, T., J.U. Frey and V. Korz, 2006. Longterm effects of brief acute stress on cellular signaling and hippocampal LTP. J. Neurosci, 26: 3951-3958.

111.Alkire, M.T. and L. Cahill, 1999. Post-learning epinephrine infusion enhances long-term free recall memory in humans. Anesthesiology, 91: U180.

112.Cahill, L. and M.T. Alkire, 2003. Epinephrine enhancement of human memory consolidation: Interaction with arousal at encoding. Neurobiol. Learn. Mem., 79: 194-198.

113.Introini-Collison, I., D. Saghafi, G.D. Novack and J.L. McGaugh, 1992. Memory-enhancing effects of post-training dipivefrin and epinephrine: Involvement of peripheral and central adrenergic receptors. Brain Res., 572: 81-86.

114.Izquierdo, I., C. Dalmaz, R.D. Dias and M.G. Godoy, 1988. Memory facilitation by posttraining and pretest ACTH, epinephrine and vasopressin administration: Two separate effects. Behav. Neurosci., 102: 803-806.

115.Gold, P.E., R. van Buskirk and J.W. Haycock, 1977. Effects of posttraining epinephrine injections on retention of avoidance training in mice. Behav. Biol., 20: 197-204.

116.Gold, P.E. and R.B. Van Buskirk, 1975. Facilitation of time-dependent memory processes with posttrial epinephrine injections. Behav. Biol., 13: $145-53$.

117.Gold, P.E., R.B. Van Buskirk and J.L. McGaugh, 1975. Effects of hormones on time-dependent memory storage processes. Prog. Brain Res., 42: 210-211.

118.Halonen, J., P.R. Zoladz, C.R. Park and D.M. Diamond, 2007. Propranolol blocks the stress-induced enhancement, but not impairment, of long-term spatial memory in adult rats. Soc. Neurosci. Abst., 37: 745.715.

119.Korol, D.L. and P.E. Gold, 2007. Epinephrine converts long-term potentiation from transient to durable form in awake rats. Hippocampus, 18: 81-91.
120.Shors, T.J., S. Levine and R.F. Thompson, 1990. Effect of adrenalectomy and demedullation on the stress-induced impairment of long-term potentiation. Neuroendocrinology, 51: 70-75.

121.Sternberg, D.B., K.R. Isaacs, P.E. Gold and J.L. McGaugh, 1985. Epinephrine facilitation of appetitive learning: Attenuation with adrenergic receptor antagonists. Behav. Neural Biol., 44: 447-453.

122.Gelinas, J.N. and P.V. Nguyen, 2005. Betaadrenergic receptor activation facilitates induction of a protein synthesis-dependent late phase of longterm potentiation. J. Neurosci., 25: 3294-3303.

123.Introini-Collison, I.B., C. Castellano and J.L. McGaugh, 1994. Interaction of GABAergic and beta-noradrenergic drugs in the regulation of memory storage. Behav. Neural. Biol., 61: 150-155.

124.Gray, R. and D. Johnston, 1987. Noradrenaline and beta-adrenoceptor agonists increase activity of voltage-dependent calcium channels in hippocampal neurons. Nature, 327: 620-622.

125.Lupien, S.J. and M. Lepage, 2001. Stress, memory and the hippocampus: can't live with it, can't live without it. Behav. Brain Res., 127: 137-158.

126.Diamond, D.M., M.C. Bennett, M. Fleshner and G.M. Rose, 1992. Inverted-U relationship between the level of peripheral corticosterone and the magnitude of hippocampal primed burst potentiation. Hippocampus, 2: 421-430.

127.Lupien, S.J., C.J. Gillin and R.L. Hauger, 1999. Working memory is more sensitive than declarative memory to the acute effects of corticosteroids: A dose-response study in humans. Behav. Neurosci., 113: 420-430.

128.Lupien, S.J., C.W. Wilkinson, S. Briere, C. Menard, N.M.K.N. Kin and N.P.V. Nair, 2002. The modulatory effects of corticosteroids on cognition: studies in young human populations. Psychoneuroendocrinology, 27: 401-416.

129. Conrad, C.D., S.J. Lupien and B.S. McEwen, 1999. Support for a bimodal role for Type II adrenal steroid receptors in spatial memory. Neurobiol. LearningMemory, 72: 39-46.

130.Pavlides, C., Y. Watanabe, A.M. Magarinos and B.S. McEwen, 1995. Opposing Roles of Type-I and Type-Ii Adrenal-Steroid Receptors in Hippocampal Long-Term Potentiation. Neuroscience, 68: 387-394.

131.Conrad, C.D., S.J. Lupien, L.C. Thanasoulis and B.S. McEwen, 1997. The effects of Type I and Type II corticosteroid receptor agonists on exploratory behavior and spatial memory in the Ymaze. Brain Res., 759: 76-83. 
132.Pavlides, C., A. Kimura, A.M. Magarinos and B.S. McEwen, 1995. Hippocampal homosynaptic long-term depression depotentiation induced by adrenal-steroids. Neuroscience, 68: 379-385.

133. Oitzl, M.S. and E.R. de Kloet, 1992. Selective corticosteroid antagonists modulate specific aspects of spatial orientation learning. Behav. Neurosci., 106: 62-71.

134.Sandi, C. and S.P. Rose, 1994. Corticosteroid receptor antagonists are amnestic for passive avoidance learning in day-old chicks. Eur. J. Neurosci., 6: 1292-1297.

135.Venero, C. and J. Borrell, 1999. Rapid glucocorticoid effects on excitatory amino acid levels in the hippocampus: A microdialysis study in freely moving rats. Eur. J. Neurosci., 11: 2465-2473.

136.Kole, M.H.P., J.M. Koolhaas, P.G.M. Luiten and E. Fuchs, 2001. High-voltage-activated $\mathrm{Ca}_{2}+$ currents and the excitability of pyramidal neurons in the hippocampal $\mathrm{CA}_{3}$ subfield in rats depend on corticosterone and time of day. Neurosci. Lett., 307: 53-56.

137.Joels, M., E. Velzing, S. Nair, J.M. Verkuyl and H. Karst, 2003. Acute stress increases calcium current amplitude in rat hippocampus: Temporal changes in physiology and gene expression. Eur. J. Neurosci, 18: 1315-1324.

138.Zorumski, C.F. and L.L. Thio, 1992. Properties of vertebrate glutamate receptors: Calcium mobilization and desensitization. Prog. Neurobiol., 39: 295-336.

139.Rosenmund, C., A. Feltz and G.L. Westbrook, 1995. Calcium-dependent inactivation of synaptic NMDA receptors in hippocampal neurons. J. Neurophysiol., 73: 427-430.

140.Nakamichi, N. and Y. Yoneda, 2005. Functional proteins involved in regulation of intracellular $\mathrm{Ca}(2+)$ for drug development: desensitization of $\mathrm{N}$ methyl-D-aspartate receptor channels. J. Pharmacol. Sci., 97: 348-50.

141.Rosenmund, C. and G.L. Westbrook, 1993. Rundown of N-methyl-D-aspartate channels during whole-cell recording in rat hippocampal neurons: Role of $\mathrm{Ca}_{2}{ }^{+}$and ATP. J. Physiol., 470: 705-729.

142.Price, C.J., G.L. Rintoul, K.G. Baimbridge and L.A. Raymond, 1999. Inhibition of calciumdependent NMDA receptor current rundown by calbindin-D28k. J. Neurochem., 72: 634-642.

143.Adamec, R., P. Kent, H. Anisman, T. Shallow and Z. Merali, 1998. Neural plasticity, neuropeptides and anxiety in animals--implications for understanding and treating affective disorder following traumatic stress in humans. Neurosci. Biobehav. Rev., 23: 301-18.
144.Wang, H.L., M.J. Wayner, C.Y. Chai and E.H. Lee, 1998. Corticotrophin-releasing factor produces a long-lasting enhancement of synaptic efficacy in the hippocampus. Eur. J. Neurosci., 10: 3428-3437.

145.Wang, H.L., L.Y. Tsai and E.H. Lee, 2000. Corticotropin-releasing factor produces a protein synthesis-dependent long-lasting potentiation in dentate gyrus neurons. J. Neurophysiol., 83: 343-349.

146.Blank, T., I. Nijholt, K. Eckart and J. Spiess, 2002. Priming of long-term potentiation in mouse hippocampus by corticotropin-releasing factor and acute stress: implications for hippocampusdependent learning. J. Neurosci., 22: 3788-3794.

147.Chen, Y., K.L. Brunson, G. Adelmann, R.A. Bender, M. Frotscher and T.Z. Baram, 2004. Hippocampal corticotropin releasing hormone: Preand postsynaptic location and release by stress. Neuroscience, 126: 533-540.

148.Ye, L., J.S. Qi and J.T. Qiao, 2001. Long-term potentiation in hippocampus of rats is enhanced by endogenous acetylcholine in a way that is independent of N-methyl-D-aspartate receptors. Neurosci. Lett., 300: 145-148.

149. Ovsepian, S.V., R. Anwyl and M.J. Rowan, 2004. Endogenous acetylcholine lowers the threshold for long-term potentiation induction in the CA1 area through muscarinic receptor activation: In vivo study. Eur. J. Neurosci., 20: 1267-1275.

150.Lemon, N. and D. Manahan-Vaughan, 2006. Dopamine D1/D5 receptors gate the acquisition of novel information through hippocampal long-term potentiation and long-term depression. J. Neurosci., 26: 7723-7729.

151.Hopkins, W.F. and D. Johnston, 1988. Noradrenergic enhancement of long-term potentiation at mossy fiber synapses in the hippocampus. J. Neurophysiol., 59: 667-687.

152.Katsuki, H., Y. Izumi and C.F. Zorumski, 1997. Noradrenergic regulation of synaptic plasticity in the hippocampal CA1 region. J. Neurophysiol., 77: 3013-3020.

153.Izumi, Y. and C.F. Zorumski, 1999. Norepinephrine promotes long-term potentiation in the adult rat hippocampus in vitro. Synapse, 31: 196-202.

154.Lisman, J.E. and A.A. Grace, 2005. The hippocampal-VTA loop: Controlling the entry of information into long-term memory. Neuron, 46: 703-13. 